\title{
Amnésia retrógrada funcional grave: relato de caso
}

\section{Severe functional retrograde amnesia: case report}

\author{
Maila de Castro L. Neves ${ }^{1}$, Rogério Gomes Beato ${ }^{2}$, Carla Monteiro Girodo ${ }^{3}$, Hélio Lauar ${ }^{1}$, Rodrigo Nicolato ${ }^{1}$, \\ João Vinícius Salgado ${ }^{1}$, Antônio Lúcio Teixeira ${ }^{4}$ \\ ' Psiquiatra do Hospital de Ensino Instituto Raul Soares, Fundação Hospitalar do Estado de Minas Gerais (FHEMIG). \\ ${ }^{2}$ Neurologista do Hospital de Ensino Instituto Raul Soares, Fundação Hospitalar do Estado de Minas Gerais (FHEMIG). \\ ${ }^{3}$ Fonoaudióloga. \\ ${ }^{4}$ Professor de Neurologia da Faculdade de Medicina da Universidade Federal de Minas Gerais (UFMG).
}

Recebido: 08/05/2007 - Aceito: 13/07/2007

\section{Resumo}

Contexto: Uma síndrome amnésica clássica caracteriza-se por evidente prejuízo da memória anterógrada, variável e temporária amnésia retrógrada, sendo as formas não-declarativas da memória poupadas. Entretanto, publicações recentes relataram casos de prejuízo desproporcional da memória retrógrada em relação à anterógrada. Objetivos: Relatar o caso de um paciente de 26 anos de idade com um quadro grave de amnésia retrógrada, aparentemente sem fatores desencadeantes. Métodos: Entrevista psiquiátrica e avaliação neuropsicológica. Resultados: A perda de memória do paciente se estendia por toda sua vida, mas ele era capaz de adquirir e reter novas informações. Ele também apresentava prejuízos na produção e na compreensão de palavras, assim como no reconhecimento e no uso de objetos. Conclusão: A formulação diagnóstica final do caso é difícil, apontando possivelmente o contínuo existente entre a amnésia retrógrada psicogênica e a orgânica.

Neves, M.C.L. et al. / Rev. Psiq. Clín 35 (1); 26-30, 2008

Palavras-chave: Amnésia, amnésia retrógrada, psicogênico, funcional, memória.

\section{Abstract}

Background: A classic amnestic syndrome is characterized by a significant impairment of the anterograde memory, a variable and transitory retrograde amnesia with preserved non-declarative memory. However, case reports of patients with disproportionate compromise of the retrograde memory have been described in the recent literature. Objectives: To report a 26-year-old patient with a severe global retrograde amnesia with no evident triggering factor. Methods: Psychiatric interview and neuropsychological evaluation. Results: His memory loss compromised all domains of his life, although he could acquire and retain new information. He also exhibited prominent deficits in production and comprehension of common words as well as in recognition and use of objects. Discussion: The final diagnostic formulation of the present case is difficult possibly indicating a continuum between psychogenic and organic retrograde amnesia.

Neves, M.C.L. et al. / Rev. Psiq. Clín 35 (1); 26-30, 2008

Key-words: Amnesia, retrograde amnesia, psychogenic, functional, memory. 


\section{Introdução}

A amnésia pode ser definida como um estado mental patológico em que a memória e o aprendizado estão afetados em proporções maiores que as demais funções cognitivas em um paciente sem alteração do nível de consciência (Kopelman, 2002). A partir dessa conceituação clássica de amnésia, pressupõe-se que a amnésia retrógrada seja comumente acompanhada por amnésia anterógrada, ou seja, pela habilidade de reter novas informações ou aprender. Entretanto, publicações recentes relatam casos de prejuízo desproporcional da memória retrógrada em relação à anterógrada (Ross, 2000; Sellal et al., 2002; Lucchelli e Spinnler, 2002).

A compreensão da amnésia retrógrada isolada representa um grande desafio, uma vez que é difícil explicar como traços antigos de memória, presumivelmente bem consolidados, não podem ser acessados, mas novas informações podem ser retidas e recordadas (Lucchelli e Spinnler, 2002). Muitas dúvidas persistem sobre as bases neuroanatômicas envolvidas na amnésia retrógrada e sua elucidação poderá contribuir para o entendimento dos múltiplos sistemas de memória.

Neste artigo, relatamos o caso de um paciente de 26 anos de idade que desenvolve amnésia retrógrada grave, tendo a capacidade de aprendizagem preservada. O paciente conferiu o consentimento para a publicação deste relato.

\section{Relato de caso}

Trata-se de paciente do sexo masculino, 26 anos, destro, natural e residente em Raposos, Minas Gerais, casado, católico, segundo grau completo, garçom e cozinheiro.

O paciente foi encaminhado ao Hospital de Ensino Instituto Raul Soares, Belo Horizonte, no dia 8 de fevereiro de 2006. No dia 6 de fevereiro, saíra do trabalho às 21 horas, não retornando para sua casa em Raposos, região metropolitana de Belo Horizonte. Foi encontrado vagando próximo à rodoviária de Belo Horizonte no dia 8 de fevereiro.

Não se lembrava de nenhum fato relacionado à sua autobiografia, não sabia seu nome, nem reconhecia nenhum de seus familiares. Apresentava dificuldades na compreensão de palavras, nomeação de objetos e atribuição de função a estes, além de vocabulário pobre. Muitas vezes não compreendia o que lhe era perguntado. Não eram evidentes alterações da atenção, do pensamento, do afeto e do humor. Os exames físico geral e neurológico não mostraram alterações.

Segundo os familiares, antes desse quadro não houve mudança do comportamento do paciente ou quaisquer conflitos pessoais ou fatores estressantes eram evidentes. De nota na história pregressa, o paciente apresentou episódio único de perda de consciência aos 15 anos, sem relato de trauma, com movimentos tônico-clônicos gene- ralizados, tendo utilizado carbamazepina $400 \mathrm{mg} /$ dia por dois anos, sem recorrência do evento. Era tabagista, fumando cerca de 30 cigarros/dia, além consumir bebidas alcoólicas ocasionalmente, sem preencher critérios para dependência. Na família, não havia história de doenças psiquiátricas ou neurológicas.

O paciente foi submetido à ampla propedêutica complementar. Os exames laboratoriais, incluindo hemograma completo, coagulograma, glicemia de jejum, funções renal, hepática e tireoidiana, ionograma, velocidade de hemossedimentação, fator antinuclear, fator reumatóide, dosagem sérica de vitamina B12 e ácido fólico, sorologia para sífilis, hepatites B e C, HIV-1 e 2, além de pesquisa de metabólitos de cocaína e canabinóides na urina, não mostraram alterações. $\mathrm{O}$ exame de liquor também não revelou qualquer alteração. $\mathrm{O}$ eletroencefalograma mostrou atividade de base normal sem paroxismos epilépticos. Os exames de tomografia computadorizada e ressonância magnética do encéfalo foram normais. $\mathrm{O}$ exame de cintilografia tomográfica perfusional cerebral (SPECT) mostrou distribuição heterogênea do radiofármaco em córtex cerebral, com hipoperfusão frontal, temporal bilateral, predominantemente à esquerda.

No seguimento ambulatorial, o paciente dizia não se lembrar de qualquer fato ocorrido antes do dia 6 de fevereiro, mantendo dificuldades na compreensão e no uso de palavras, no reconhecimento e na utilização de objetos e conceitos culturais. Não sabia mais ler ou escrever. Afirmava também não saber mais o que era fumar.

Foi submetido à avaliação neuropsicológica, incluindo os seguintes testes: 1. Bateria de Avaliação Frontal (FAB); 2. Figura Complexa de Rey; 3. Teste de Cartas de Wisconsin; 4. Teste de Trilhas; 5 . Teste de Fluência Verbal; 6. Exame Diagnóstico de Afasia de Boston (BDAE); 7. Teste de Fluência Verbal para Eventos Autobiográficos; 8. Teste de Nomeação de Boston; 9. Teste de Aprendizagem Auditiva Verbal de Rey. O resultado dessa avaliação é mostrado na tabela 1 . Não foram detectadas alterações na memória anterógrada e nas funções executivas, com prejuízo predominante nas memórias semântica e autobiográfica.

$\mathrm{O}$ paciente passou a mostrar-se preocupado com a perda de memória, tentando aprender tudo o que lhe era comentado. Progressivamente, começou a lembrar-se de alguns fatos, especialmente eventos isolados da infância. Tais recordações apresentavam gradiente temporal, ou seja, as lembranças surgiram de acordo com a ordem em que ocorreram na vida do paciente até cerca de oito anos de idade.

Após um ano de acompanhamento, o paciente apresenta lembranças esparsas que não se articulam bem. Não consegue contextualizar o que aprende e, apesar de não exibir alterações do humor, apresenta-se socialmente isolado. Mantém-se casado, tendo mudado de cidade. Não retomou as antigas ocupações como garçom e cozinheiro, ou mesmo seus hábitos de lazer. 
Tabela 1. Resultado dos testes neuropsicológicos

\begin{tabular}{|c|c|c|}
\hline Teste & Resultado & $\begin{array}{l}\text { Habilidades cognitivas avaliadas } \\
\text { (Spreen e Strauss, 1991) }\end{array}$ \\
\hline $\begin{array}{l}\text { 1. Bateria de } \\
\text { Avaliação Frontal } \\
\text { (FAB) }\end{array}$ & $9 / 18$ & $\begin{array}{l}\text { Conceitualização, flexibilidade mental, } \\
\text { programação motora, sensibilidade à } \\
\text { interferência, controle inibitório }\end{array}$ \\
\hline $\begin{array}{l}\text { 2. Teste da Figura de } \\
\text { Rey }\end{array}$ & $\begin{array}{l}\text { Cópia }=34 / 36 \\
\text { Evocação tardia = } 29 / 36 \\
0 \text { teste revelou que ocorria retenção da aprendizagem } \\
\text { após } 30 \text { minutos }\end{array}$ & $\begin{array}{l}\text { Construção visuoespacial, memória } \\
\text { não-verbal imediata e memória não-verbal } \\
\text { tardia }\end{array}$ \\
\hline $\begin{array}{l}\text { 3. Teste de Cartas de } \\
\text { Wisconsin (versão } \\
128 \text { cartas) }\end{array}$ & 6/6 critérios; 2 erros; 1 perseveração & $\begin{array}{l}\text { Raciocínio abstrato e flexibilidade } \\
\text { mental como resposta a mudanças nas } \\
\text { contingências ambientais }\end{array}$ \\
\hline 4. Teste de Trilhas & Dificuldades em reconhecer seqüência numérica (contar) & $\begin{array}{l}\text { Flexibilidade mental, atenção alternada e } \\
\text { impulsividade, ou seja, verifica a capacidade } \\
\text { de alternância entre categorias cognitivas }\end{array}$ \\
\hline $\begin{array}{l}\text { 5. Teste de Fluência } \\
\text { Verbal }\left(60^{\prime}\right)\end{array}$ & $\begin{array}{l}\text { Animais: } 6 \\
\text { (valor de referência: } 15 \text { para } 8 \text { anos escolaridade) (Brucki } \\
\text { et al., 1997) } \\
\text { Frutas: 11; itens de supermercado: } 7 \text {; nome de aves: } 3 \text {; } \\
\text { nome de cores: } 6\end{array}$ & Fluência verbal semântica, categorização \\
\hline $\begin{array}{l}\text { 6. Exame Diagnóstico } \\
\text { de Afasia de Boston } \\
\text { (BDAE) }\end{array}$ & $\begin{array}{l}\text { Alteração na discriminação de palavras: } 57 \text { pontos; } \\
\text { identificação de partes do corpo: } 16 \text { pontos; seqüências } \\
\text { automatizadas: } 6 \text { pontos; reconhecimento de palavras: } 6 \\
\text { pontos; ditado e soletração: } 3 \text { pontos; fluência semântica } \\
\text { (animais): } 28 \text { (Mansur et al., 2005). }\end{array}$ & $\begin{array}{l}\text { Compreensão e expressão de linguagem } \\
\text { verbal oral e escrita }\end{array}$ \\
\hline $\begin{array}{l}\text { 7. Teste de Fluência } \\
\text { Verbal para Eventos } \\
\text { Autobiográficos }\end{array}$ & $\begin{array}{l}\text { Prejuízo generalizado em todas as modalidades avaliadas, } \\
\text { com preponderância de lembranças de conteúdo } \\
\text { emocional. Gradiente temporal para os fatos evocados. } \\
0 \text { paciente se lembrou de fatos apenas até os } 11 \text { anos de } \\
\text { idade, não conseguindo localizar as lembranças no tempo }\end{array}$ & Memória autobiográfica (Piolino et al., 2000) \\
\hline $\begin{array}{l}\text { 8. Teste de Nomeação } \\
\text { de Boston (TNB) }\end{array}$ & $\begin{array}{l}45 / 60 \text { pontos (valor de referência: média } 47.4 \text { (6), ponto de } \\
\text { corte de } 1-8 \text { anos de escolaridade: } 25 \text { pontos) (Mansur et } \\
\text { al., 2005). }\end{array}$ & $\begin{array}{l}\text { Nomeação por confronto visual, memória } \\
\text { semântica }\end{array}$ \\
\hline $\begin{array}{l}\text { 9. Teste de } \\
\text { Aprendizagem } \\
\text { Auditiva Verbal de } \\
\text { Rey }\end{array}$ & $\begin{array}{l}A 1=3, A 2=9, A 3=11, A 4=11, A 5=9, B 1=4, A 6=7, A 7=11 \\
\text { (valores médios para população brasileira: } A 1=6, A 2=8, \\
A 3=9, A 4=11, A 5=12, B 1=4, A 6=10, A 7=10 \text { ) (Diniz et } \\
\text { al., 2000) } \\
\text { Os resultados revelaram curva semelhante aos controles, } \\
\text { ou seja, compatível com o aprendizado. } 0 \text { paciente não } \\
\text { apresentou curva de amnésia anterógrada }\end{array}$ & $\begin{array}{l}\text { Memória recente, aprendizagem, } \\
\text { interferência, retenção e memória de } \\
\text { reconhecimento }\end{array}$ \\
\hline
\end{tabular}

\section{Discussão}

Uma síndrome amnésica clássica caracteriza-se por evidente prejuízo da memória anterógrada, variável e temporária amnésia retrógrada, sendo as formas nãodeclarativas da memória poupadas (Kritchevsky et al., 2004). Esse tipo de amnésia é comumente relacionado a lesões orgânico-cerebrais secundárias a hipóxia, trauma, encefalite, síndrome de Korsakoff e doença de Alzheimer, cursando com comprometimento bilateral dos lobos temporais mediais e/ou de estruturas diencefálicas (Kritchevsky et al., 2004; Scoville e Milner, 1957).
Em contraste com esse comprometimento da memória, com bases orgânicas definidas, existe uma condição mais rara em que os pacientes desenvolvem uma grave amnésia retrógrada, sem comprometimento da memória anterógrada e sem qualquer sinal de lesão ou doença cerebral. Tais casos apresentam tipicamente instalação aguda e marcante perda da identidade pessoal, sendo bastante semelhantes ao descrito no presente relato (Sellal et al., 2002, Kritchevsky et al., 2004). Apesar de não haver consenso entre os autores, o termo amnésia retrógrada funcional é empregado para descrever esses casos em que a etiologia não pode ser classificada pre- 
cisamente como orgânica ou psicogênica (Sellal et al., 2002; Hodges, 2002; De Renzi, 2002).

As regiões e os circuitos neurais envolvidos na amnésia retrógrada não estão precisamente definidos. Estudos de neuroimagem funcional sugerem que circuitos envolvendo o córtex frontal, temporal e o tálamo participariam do armazenamento e da recuperação de memórias remotas (Kopelman, 2002). Os lobos frontais contribuiriam para o planejamento, a monitorização e a organização dos processos de recuperação da memória remota, particularmente quando é necessária uma reconstrução mais elaborada (Kopelman, 2002; Scoville e Milner, 1957). Os lobos temporais direitos parecem ser relevantes para a reconstrução de processos em que imagens visuais ou multimodais são necessárias para a recordação de eventos autobiográficos (Kopelman, 2002; Scoville e Milner, 1957). Por outro lado, o lobo temporal medial esquerdo parece ser crucial para o armazenamento e o acesso à informação semântica e lexical (Scoville e Milner, 1957). Estudos mostraram que lesões temporais extensas e frontais podem produzir grave amnésia retrógrada, mas existem controvérsias acerca do resultado de lesões diencefálicas ou temporais mediais (Kopelman, 2002).

Em relação especificamente às memórias autobiográficas, não se pode afirmar que elas estejam armazenadas em um local específico do cérebro, mas provavelmente distribuídas em todo o córtex. Assim, é possível especular que vários padrões de lesão poderiam resultar em perda de memória autobiográfica, incluindo, por exemplo, lesões em substância branca relacionadas à conexão córtico-cortical. Por sua vez, a perda de memória autobiográfica em pacientes com demência semântica, que exibem atrofia temporal anterior, sugere que esse tipo de memória depende, pelo menos em parte, do lobo temporal, responsável pela integração do conhecimento semântico (Hodges, 2002).

No caso relatado, não há evidências de comprometimento estrutural de áreas encefálicas. É importante salientar, no entanto, o resultado do SPECT cerebral, que mostrou hipoperfusão em áreas frontotemporais, regiões potencialmente relacionadas às memórias retrógada e autobiográfica. Na realidade, essas alterações de perfusão, apesar de sugerirem disfunção nesses circuitos, não necessariamente comprovam que amnésia seja orgânica, definida como amnésia conseqüente à lesão cerebral ou deficiência metabólica. Isso porque uma série de estudos de neuroimagem funcional demonstrou, de forma consistente, alterações em síndromes conversivas ou mesmo na simulação (Baddeley et al., 2002; Kritchevsky et al., 2004). Por outro lado, é importante destacar o relato de Sellal et al. (2002), que descreveram um caso de perda de memória retrógrada após traumatismo cranioencefálico. A amnésia incluía também memória autobiográfica, sendo constatada disfunção na região temporal no SPECT cerebral. Após a recuperação cognitiva do paciente, houve normali- zação do padrão do SPECT. Nesse caso, supõe-se que o paciente não tinha perdido suas memórias, apenas apresentado dificuldades em acessá-las, o que poderia estar acontecendo no presente caso.

Vários fatores sugerem etiologia orgânica na amnésia retrógrada, incluindo: (1) manifestação do déficit de memória após traumatismo cranioencefálico, quadro tóxico-metabólico ou outros eventos de dano cerebral; (2) sinais neurológicos associados ao déficit cognitivo; (3) padrão de prejuízo cognitivo inclui perda de habilidades que possuem lateralização; (4) memória para fatos recentes menos comprometida que para eventos remotos; (5) existência de um gradiente temporal sem perda da identidade; (6) recuperação da função de forma parcial; (7) ausência de história psiquiátrica prévia; (8) ausência de evidência de ganho secundário (Ross, 2000). Considerando que o paciente apresentava curva de aprendizado nos testes neuropsicológicos, não exibia história pregressa de tratamentos psiquiátricos ou sinais de ganho secundário e evoluiu com melhora parcial dos sintomas, conclui-se que o caso descrito apresenta alguns itens como possíveis indicadores de organicidade.

Um diagnóstico alternativo para o caso seria amnésia psicogênica global que poderia ser basicamente de dois tipos: estado de fuga e perda de memória remota persistente (Ross, 2000). Casos de amnésia psicogênica são geralmente precedidos por grande estresse emocional e possuem história pregressa de eventos semelhantes ou tratamento psiquiátrico. Kopelman (2002) propõe inclusive que um grave estresse poderia afetar o sistema de controle executivo frontal, inibindo a recordação de memórias episódicas autobiográficas. Ressalta-se, no entanto, que a aparente ausência de transtorno psiquiátrico ou situações estressantes prévias ao evento não significa que fatores psicodinâmicos não tenham influenciado a instalação do quadro amnésico do paciente relatado. Alguns autores descreveram casos de pacientes com dano neurológico e amnésia retrógrada em que fatores psicogênicos interferiram significativamente no quadro (Baddeley et al., 2002). Ainda, Markowitsch (2002) descreveu um caso de amnésia funcional em que o tratamento simultâneo com antidepressivos e psicoterapia resultou em melhora cognitiva e do padrão de metabolismo cerebral, sugerindo que separar os mecanismos de amnésia orgânica e psicogênica poderia ser uma simplificação.

Amnésia por simulação seria uma terceira possibilidade diagnóstica. Zago et al. (2004) descreveram um caso de amnésia retrógrada por simulação e revisaram as principais estratégias cognitivas para a detecção de simulação. Há geralmente inconsistências nos testes neuropsicológicos como, por exemplo, a ausência de distinção de desempenho entre os testes mais complexos e os mais simples, o que não aconteceu no presente relato (Zago et al., 2004). 
A formulação diagnóstica final do caso é difícil, apontando possivelmente o contínuo existente entre a amnésia retrógrada psicogênica e a orgânica (Markowitsch, 2002). Dessa forma, uma abordagem direcionada para fatores etiológicos únicos ou excludentes talvez não seja a melhor perspectiva. A compreensão da complexidade dos sintomas e dos múltiplos fatores envolvidos seria a primeira etapa para a reabilitação de casos como $o$ relatado.

\section{Referências}

Baddeley, A.D.; Kopelman, M.D.; Wilson, B.A. - The handbook of memory disorders. $2^{\text {nd }}$ ed. John Wiley \& Sons, Chichester, 2002.

Brucki, S.M.D.; Malheiros, S.M.F.; Okamoto, I.H.; Bertolucci, P.H.F. - Dados normativos para o teste de fluência verbal: categoria animais em nosso meio. Arq Neuropsiquiatr 55: 56-61, 1997.

De Renzi, E. - What does psychogen mean? Cortex 38: 678-681, 2002.

Diniz, L.F.M.; Cruz, M.F.; Torres, V.M.; Cosenza, R.M. - 0 teste de aprendizagem auditivo-verbal de Rey: normas para uma população brasileira. Rev Bras Neurol 36: 79-83, 2000.

Hodges, J.R. - Pure retrograde amnesia exists but what is the explanation? Cortex 38: 674-677, 2002.
Kopelman, M.D. - Disorders of memory. Brain 125: 2152-2190, 2002.

Kritchevsky, M.; Chang, J.; Squire, L.R. - Functional amnesia: clinical description and neuropsychological profile of 10 cases. Learning and Memory 11: 213-226, 2004.

Lucchelli, F.; Spinnler, H. - The "psychogenic" versus "organic" conundrum of pure retrograde amnesia: is it still worth pursuing? Cortex 38: 665669, 2002.

Mansur, L.L.; Radanovic, M.; Taquemori, L.; Greco, L.; Araújo, G.C. - A study of the abilities in oral language comprehension of the Boston Diagnostic Aphasia Examination - Portuguese version: a reference guide for the Brazilian population. Braz J Med Biol Res 38: 277-292, 2005.

Markowitsch, H.J. - Functional retrograde amnesia: mnestic block syndrome. Cortex 38: 651-654, 2002.

Piolino, P.; Desgranges, B.; Eustache, F. - La mémoire autobiographique: théorie et pratique. Solal Editeurs, Marseille, 2000.

Ross, S.M. - Profound retrograde amnesia following mild head injury: organic or functional? Cortex 36: 521-537, 2000.

Scoville, W.B.; Milner, B. - Loss of recent memory after bilateral hippocampal lesions. J Neurol Neurosurg Psychiatry 20: 11-21, 1957.

Sellal, F.; Manning, L.; Seegmuller, C.; Scheiber, C.; Schoenfelder, F. - Pure retrograde amnesia following a mild head trauma: a neuropsychological and metabolic study. Cortex 38: 499-509, 2002.

Spreen, 0.; Strauss, E. - A compedium of neuropsychological tests. Oxford University Press, New York, 1991.

Zago, S.; Sartori, G.; Scarlato, G. - Malingering and Retrograde Amnesia: The Historic Case of the Collegno Amnesic. Cortex 40: 519-532, 2004. 